Sebelas Maret Business Review Vol. 5, No. 1, pp. 27-33

ISSN: 2528-0627 (print) / 2528-0635 (online)

Copyright (@ Magister Manajemen Universitas Sebelas Maret

Homepage: https://jurnal.uns.ac.id/smbr

\title{
The Effect of Work Experience and Rigidity on The Escalation of Commitments in Investment Decisions
}

\author{
Ign. Advent Susilojati ${ }^{*, 1}$ | Widi Hidayat ${ }^{2}$ | Ake Wihadanto $^{3}$ \\ ${ }^{1}$ Department of Management, Universitas Terbuka, Indonesia \\ ${ }^{2}$ Department of Accounting, Universitas Airlangga, Indonesia \\ ${ }^{3}$ Department of Economic Development, Universitas Terbuka, Indonesia
}

\begin{abstract}
Escalation of commitment is a form of cognitive bias that has characteristics where decision-makers tend to increase their commitment to an unfavorable investment. This study aims to prove the demographic factors of decision-makers such as work experience and rigid thinking as determinants of escalation of commitment. This research applies a $2 \times 2$ factorial experimental research design with a case study as an instrument of investment decision making. The participants of this experiment were regular undergraduate students as a proxy for inexperienced decision-makers and non-regular undergraduate students (executive class) as experienced proxy for decision-makers. Participants were selected using a purposive sampling technique with the adequacy criteria for General Point Average (GPA) above 3.00 and have attended and passed the Financial Management course and Theory of Decision Making course. This research uses two-ways ANOVA with a significance level of $5 \%$. Using total 64 respondents, the results showed that work experience and rigid thinking have a significant effect on the escalation of commitment. This study also proves that the interaction between work experience and the rigidity of the decision-making mindset does not affect the level escalation of commitment.
\end{abstract}

Keywords: Decision making, escalation of commitment, work-experience, rigid thinking, experimental research

\section{Background}

Decision making is a managers' systematic process in determining problems, evaluating alternatives and choosing the optimal to provide maximum benefit to the organization. Managers' decisions related to the company's future are often influenced by business decisions in the previous period. The interrelation of future decision making by past decisions is influenced by emotional ties, responsibilities and commitments. Managers often retain their commitments and responsibilities when getting negative feedback on their past business decisions. This condition is called the escalation of commitment (Bazerman, 1994). The same thing was also expressed by Staw (1997) who stated that in uncertain conditions, managers would choose to stick to their decisions even though they knew their decisions were not favorable. The irrational decision is caused by perceptual bias, judgmental bias, impression management and competitive irrationality (Bazerman, 1994).

\footnotetext{
* Corresponding author at Jl. Cabe Raya, Pondok Cabe, Pamulang, Tangerang Selatan 15418. Email: ignatiusadvent@gmail.com
} 
In prospect theory, each decision is made after information is first filtered through the decision maker 'decision frame' (Kahneman and Tversky, 1979). In the context of investment decisions, a decision maker who receives negative feedback on his previous investment decision will see himself in loss position, and will view the next decision as a choice between a definite loss that has occurred (i.e. choosing not to continue the action of adding investment) or a loss in an uncertain future (i.e. take the risk of adding funds in the hope of getting a positive return). In this situation, decision makers tend to look for risk, choosing uncertain losses that give hope of improvement compared to certain losses by increasing investment.

The agency theory framework explains that managers in decision making are motivated by their own interests due to asymmetric information between managers and owners. Managers who have private information will act in their own self-interest and not maximize the benefits expected by company owners. Reflected by continuing to finance the project even though it indicates failure or loss (Rutledge and Karim, 1999).

While the framework of self-justification theory explains that when someone believes in two conflicting things, this condition will produce cognitive dissonance (incompatibility of understanding) that causes discomfort (dissonance). Because dissonance produces uncomfortable feelings, individuals will strive to reduce levels of dissonance by changing their beliefs. Commitment escalation occurs when the manager receives project feedback (the level of sales that fail and decreases) is not consistent with generative cognition (expected profitability), so the dissonant cognition is made as a representation of knowledge that the project is not profitable and therefore the project must be closed.

Managers' decisions related to the future of business are also influenced by the character of managers, one of which is the rigidity of thinking. The stiffness of thinking causes managers who already have experience unable to map and solve problems, causing their decisions to be biased. The manager's perspective becomes increasingly dichotomous so that it is as if the alternative problem solving is a past decision (Mark et al., 2013).

From another research group, De Bruin et al., (2007) who developed the Adult Decision-Making Competence (A-DMC) measurement tool, found that participants who scored high in A-DMC tended to have less negative life experiences, where negative life experiences were interpreted as indicators of decision making that were not rational. Rationality as a framework for thinking consists of two components, fluid rationality and crystallized rationality. Fluid rationality will be related to basic abilities or innate abilities in reflective thinking that help a person make rational decisions. Crystallized rationality is related to knowledge that can drive rational thinking. Knowledge is impossible to achieve without experience or formal education (Stanovich and West, 2014).

Based on theory and previous research, additional studies are needed because certain differences in the characteristics of subjects can make a difference in results. This research is expected to be able to provide evidence that "certain differences" such as work experience and rigid thinking that may influence the escalation of commitment in investment decision making.

\section{Method, Sample and Data Analysis}

This study uses a $2 \times 2$ experimental design form between subjects with two treatments in two different conditions: with experience, without experience, rigid thinking and un-rigid thinking, as can be seen in the following table:

Table 1. Experiment Matrix

\begin{tabular}{ccccc}
\hline & & \multicolumn{2}{c}{ Experience } & \multirow{2}{*}{ Total } \\
\cline { 3 - 4 } & & With & Without & \\
\hline \multirow{2}{*}{ Rigid Thinking } & Rigid & C1 & C2 & C7 \\
& Unrigid & C3 & C4 & C8 \\
\hline Total & & C5 & C6 & C8 \\
\hline
\end{tabular}


The subjects of this study were students of Universitas Widya Mandala students who were selected using the purposive sampling technique using the following criteria: (1) Regular students and executive class students to represent treatment experiences; (2) Have a minimum Grade Point Average (GPA) of 3.00; (3) Has taken courses in Advanced Financial Management and Decision Making Theory with a minimum grade of $\mathrm{B}$.

Experienced participants are represented in column C5 Table 1. C5 Participants consist of all executive class students who meet the criteria: 1) A Project Leader; 2) Have a minimum staff of 5 people and; 3) Have made business decisions related to corporate finance. The number of Executive class students who meet these criteria is 45 people. To provide assurance that participants have the cognitive ability to do calculation in investment case study, the 45 existing participants is filtered again using criteria minimum GPA of 3.00 and have taken courses in Advanced Financial Management and Decision-Making Theory with a minimum grade of B. So that the final number of experienced participants who meet the criteria as experimental subjects is 30 people. The amount is then divided equally into columns $\mathrm{C} 1$ and $\mathrm{C} 3$ for each of 15 participants. 15 Participants in column $\mathrm{C} 1$ will be given rigid treatment, while the remaining 15 participants in column $\mathrm{C} 3$ will be given non-rigid treatment.

The same rules apply for non-experience participants. Non-experience participants are in column C6 Table 1 Experiment Matrix. Because it represents non-experienced participants, the criteria for having staff and ever making business decisions are nullified. From the total 89 non-experienced participants, 34 were then filtered to meet the criteria of Have a minimum Grade Point Average (GPA) of 3.00 and has taken courses in Advanced Financial Management and Decision-Making Theory with a minimum grade of B. These criteria are needed for provides a guarantee for participants to understand case studies of financial investment. The existing 34 participants is then divided equally into columns C2 and C4. Seventeen participants in column $\mathrm{C} 2$ will be given rigid treatment, while the remaining 17 participants in column $\mathrm{C} 4$ will be given non-rigid treatment. The result of purposive sampling is presented in Table 2.

Table 2. Sampling Guide for Stratified Purposive Sampling of Participants

\begin{tabular}{|c|c|c|c|}
\hline \multirow{2}{*}{ No } & \multirow{2}{*}{ Criteria } & \multicolumn{2}{|c|}{ Condition } \\
\hline & & Experienced & Non-Experienced \\
\hline 1 & Population & & \\
\hline & $\begin{array}{l}\text { Participants consist of all executive class students who meet the } \\
\text { criteria: } \\
\text { 1) A Project Leader; } \\
\text { 2) Have a minimum staff of } 5 \text { people and; } \\
\text { 3) Have made business decisions related to corporate finance }\end{array}$ & 45 & 89 \\
\hline 2 & GPA $<3.00$ & (3) & (20) \\
\hline 3 & Has a minimum Grade Point Average (GPA) of 3.00 & 42 & 69 \\
\hline 4 & $\begin{array}{l}\text { Has taken courses in Advanced Financial Management and } \\
\text { Decision-Making Theory with grade }<\mathrm{B}\end{array}$ & (12) & (35) \\
\hline 5 & $\begin{array}{l}\text { C1 Experience-Rigid } \\
\text { C2 Non-Experienced-Rigid } \\
\text { C3 Experience-Non-Rigid } \\
\text { C4 Non-Experienced- Non-Rigid }\end{array}$ & $\begin{array}{l}15 \\
15\end{array}$ & $\begin{array}{l}17 \\
17\end{array}$ \\
\hline
\end{tabular}

The dependent variable observed in each condition is the level of commitment escalation. The instruments used in this study are the adoption, adaptation and combination of the Rutledge and Karim (1999) with some adjustments so that they are more in line with the actual conditions and conditions in Indonesia. The commitment escalation variable in the instrument is measured through the tendency of respondents to continue their project. This tendency is expressed in terms of the percentage of willingness to continue the project, where $0 \%$ indicates the unwillingness to continue the project and $100 \%$ which shows the desire to continue the project. Rigid Thinking manipulation will be applied by presenting information about the manager's character. Rigid managers will look at just one measurement tool to assess an investment, while non-rigid managers will consider other information. Work experience will be seen 
from the position and length of the respondent's tenure. The analysis technique uses two-ways ANOVA with a significance level of $5 \%$.

\section{Result}

The result of the normality test is presented in Table 3. All the significant values (or $p$ values) of two tests were found to be higher than 0.05 . If a significant value is higher than 0.05 , it interprets that the data is normally distributed (e.g., Kim and Bang, 2016).

Homogeneity testing was applied using the Levene's test to ensure all four treatments (experiencerigid, non-experience-rigid, experience-non-rigid, non-experience-non-rigid) have the same variance. Based on the results of statistical tests show a significance value of 0.177 or above Sig. 0.05 so it can be concluded that the variance of the commitment escalation variable is homogeneous.

The results of the SPSS Test of Between-Subjects Effects were used to test the hypothesis of this study. If the significance (Sig.) $<0.05$ then there is a difference in commitment escalation (tendency to continue the project) based on factor variables. In contrast, if the significance $>0.05$ then there is no difference in commitment escalation (tendency to continue the project) based on factor variables. The output of hypothesis testing can be seen also in the following Table 3.

Table 3 Regression Result (Tests of Between-Subjects Effects)

\begin{tabular}{|c|c|c|}
\hline Variable & $\mathrm{F}$ & Sig. \\
\hline Work Experience & 7.319 & $0.009 * * *$ \\
\hline Rigidity & 7.581 & $0.008^{* * *}$ \\
\hline Work Experience*Rigidity & 1.629 & 0.207 \\
\hline Constant & 622.537 & $0.000 * * *$ \\
\hline Kolmogorov-Smirnov Test & .084 & 0.200 \\
\hline Shapiro-Wilk Test & .978 & 0.316 \\
\hline Levene's Test & 1.700 & 0.177 \\
\hline R-Square & \multicolumn{2}{|c|}{0.221} \\
\hline Adj R-Square & \multicolumn{2}{|c|}{0.182} \\
\hline Observation & \multicolumn{2}{|c|}{30} \\
\hline
\end{tabular}

The p-value of work experience is 0.009 . This value is smaller than 0.05 , which means there is a difference in the escalation of commitments to continue losing projects between respondents who have experience and managers who do not have work experience. There are three factors that cause work experience to influence the tendency of escalation in a financial decision making.

First, the demands of the working social environment that compel decision makers to be in a position to assess their business decisions. This situation is well explained by Staw (1981) who explains that there are two justifications used by decision makers to assess the quality of decision making, internal justification and external justification. Internal justification is the way in which decision makers try to do everything possible to protect their good name. Whereas external justification is an attempt by decision makers to defend or account for their business decisions from evaluations, assessments by outsiders and prove that their business decisions are correct. This external justification came to be known as impression management, which was defined by Bazerman (1994) as the motivation of managers to manipulate other parties' perceptions of their performance aimed at preserving reputation, self-image and good name.

Second, consistency norms in decision making. Staw (1981) explains that the consistency of decision making by a manager influences people's judgment of a manager. A leader who is often inconsistent in making a business decision will be judged worse than a leader who is consistent in every decision making. Internalization of norms of consistency in decision making is obtained through the work experience of a leader from year to year. 
Third, the decision-making approach. The results of research conducted by Anderson and Maletta (1994) states that the more familiar with the job, the manager will be more courageous to take a decision. Conversely, if a manager is still inexperienced it will tend to take decisions conservatively. So that in the context of decision making under uncertain conditions, decision makers who have more experience will be more likely to escalate than decision makers who lack work experience. The results of this study are in line with the hypotheses proposed experience influencing the escalation of investment decision making commitments, with a significance value of p-value 0.009 with an average tendency of experienced decision makers to continue losing projects is $54.3 \%$, this value is higher than the tendency inexperienced investment decision makers who only $43.7 \%$ as it can be seen in the Table 4.

Table 4. Escalation - Work Experience and Rigid Thinking

\begin{tabular}{lcc}
\hline Variable & Mean & S.D. \\
\hline Work Experience & & \\
With & 0.543 & 0.029 \\
Without & 0.437 & 0.027 \\
Rigid Thinking & & \\
With & 0.544 & 0.028 \\
Without & 0.436 & 0.028 \\
\hline
\end{tabular}

The p-value of the rigid thinking variable is worth 0.008 . This value is smaller than 0.05 , which means that there is a difference in the escalation of commitments to continue loss-making projects between respondents who have rigid thinking and managers who don't have rigid thoughts. Rigidity causes people to repeatedly apply the same behavior to different business situations. This is because decision makers are most comfortable in doing what they know or did in the past. The perspective on the problem becomes increasingly dichotomous, as if the only solution is the decision it offers.

A manager who has rigid thinking tends to think rigidly and biased in decision making. Under uncertain condition, respondents who are given rigid treatment will tend to refer to prior business decisions as the only major consideration of continuing unfavorable project. The results of this study are in line with the hypothesis that rigid thinking influences the commitment escalation, with a significance value of $\mathrm{p}$ value 0.008 . The average tendency of decision makers who think rigidly to continue projects that are unfavorable is $54.5 \%$, this average is higher than respondents who do not think rigidly by $43.6 \%$ as it can be seen in the Table 4.

The p-value of the interaction between work experience interaction variable and rigid thinking (experience $*$ rigidity) is worth 0.207 . This value is greater than 0.05 , which means there is no interaction of work experience with rigidity in determining the escalation of a manager's commitment to continuing an unfavorable investment project. The insignificance of the interaction shows that there is no contribution of work experience in reducing the impact of commitment escalation on rigid-minded respondents.

\section{Discussion}

Mainstream economic theory view homo economicus as a rational human being (Simon, 1955). Every action is carried out by homo economicus based on two things, first utility maximization, which is every action is taken to get maximum benefit. Second, profit maximization, which is individuals are agents who are able to calculate the consequences of each alternative action. Another characters of homo economicus are has a stable and well-defined preference, has the ability to do perfect calculation (perfect computational ability), prioritizing personal interests (unbounded selfishness), and has unlimited will power or unbounded will-power. In a paper written in French, with a summary in English, Allais (1953) describes the results of experiments that show that individual decisions are not always rational, and therefore not consistent with expected utility theory.

Another psychological construct that is most often associated with rationality, or even seen as identical with rationality, is intelligence. In addition they both rationality and intelligence represent good 
thinking processes and good outcomes (Baron, 2008). However, Stanovich and West (2014) argue that rationality is different from intelligence. Intelligence is defined as the ability of someone to take a standardized test to measure indicators of cognitive ability. From empirical studies produced two concepts of intelligence consisting the concept of fluid intelligence (Gf) and crystallized intelligence (Gc). Gf reflects the ability of reasoning in various domains of life whereas Gc reflects declarative knowledge gained from learning experiences during an individual's psychological development. Neither the test that measures Gf nor the test that measures Gc does measure the level of rationality in judgment and decision making. Individuals with low Gf and Gc are not more likely to do side bias compared to individuals who have higher Gf and Gc (Stanovich et al., 2013; Stanovich and West, 2007).

Crystallized intelligence obtained during work experience and will no longer be considered in decision making. This condition can be explained through the concept of Locus of Control which is the decision maker control of their work and their belief in self-success. There are two locus of control. Firstly, the internal locus of control that believes success is determined by one's own abilities. Decision makers who have an internal locus of control type will rely more on themselves. A manager who has a high internal locus of control, although having work experience will not reduce the tendency of escalation because it will strengthen the effect of rigid thinking. Second, the external locus of control explaining that success is determined by other people or factors outside the decision maker. Therefore, the characteristic of decision makers with an external type of locus of control is that individual behavior will not play a role in achieving goals. From the explanation above, it can be seen that the weak influence of the interaction of work experience and rigid thinking on the escalation of commitment is influenced by locus of control, especially those of internal locus of control.

Moreover, Stanovich and West (2007) report on their research which examines individual differences in judgment factors. In that research, it was revealed that judgments made by participants deviated systematically when compared with normatively applicable standards. Thus, this study confirms the notion of trait rationality as an individual differentiating factor such as conjunction fallacy, gambler's fallacy and myside bias. Conjunction fallacy namely individual conditions give more weight to information about specific conditions, ignoring information about general conditions that are actually more relevant in the judgment task being carried out. Gambler's fallacy is a condition of judgment deviation that occurs when individuals have the belief that if something that happens in a row is considered to be deviating from the habit, then the possibility for it to happen again in the next period will be less than the actual probability. Conversely, something that does not appear or does not happen as usual, the individual believes that the probability to appear at a later time is greater than the actual probability. Myside bias is a deviation in judgment; in the form of a tendency to search for, remember, and interpret information so that the information confirms the beliefs or conjectures that were previously held. On the other hand, individuals show a tendency to ignore other possibilities that actually make sense.

\section{Conclusion}

Everyone should think and act rationally. Disobedience to this norm will cause a person to incur losses in one form or another. There have been many studies examining how individuals act irrationally. On the other hand, individual differences in nationality have not been much studied. Work experience and rigid thinking are factors that influence the escalation of commitment. However, the strength of work experience is not able to reduce the effect of escalation of commitment on rigid-minded respondents. Individual character greatly influences the success of work experience reducing escalation commitment. This study confirms the notion of trait rationality as an individual differentiating factor such as conjunction fallacy, gambler's fallacy and myside bias. Because of the importance of rationality, the business world needs precise, accurate and reliable measurement of rationality. With valid measurement tools we can develop the rational ability of financial managers and on the other hand we can select financial managers who have good rationality.

\section{References}

Anderson, B.H. and Maletta, M. (1994), "Auditor Attendance to Negative and Positive Information: The Effect of 
Experience-related Differences", Behavioral Research in Accounting, Vol. 6, pp. 1-30.

Baron, J. (2008), Thinking and Deciding. Cambridge, Cambridge University Press.

Bazerman, M.H. (1994), Judgmental in Manajerial Decision Making, John Wiley \& Son. Inc, Singapore.

De Bruin, W.B., Parker, A.M. and Fischhoff, B. (2007), "Individual Differences in Adult Decision-Making Competence", Journal of Personality and Social Psychology, Vol. 92 No. 938-956.

Kahneman, D. and Tversky, A. (1979), "Prospect Theory an Analysis of Decisions under Risk", Econometrica, Vol. 47, pp. 263-291.

Kim, J. and Bang, H. (2016), “Three common misuses of P values”, Dental Hypotheses, Vol. 7 No. 3, pp. 73-80.

Mark, Y., Mary, H. and Timothy., F. (2013), Tutorial Flexibility versus Rigidity in Thinking and Behavior.

Rutledge, R.W. and Karim, K.E. (1999), "The influence of self-interest and ethical considerations on managers' evaluation judgments", Accounting, Organizations and Society, Vol. 24 No. 2, pp. 173-184.

Sekaran, U. (2013), Research Methods for Business: A Skill-Building Approach, 4th ed., John Wiley \& Son. Inc, Singapore.

Simon, B.H.A. (1955), “A Behavioral Model of Rational Choice”, Quarterly Journal of Economics, Vol. 69, pp. 99 118.

Stanovich, K.E. and West, R.F. (2007), "Natural myside bias is independent of cognitive ability", Thinking and Reasoning, Vol. 13 No. 3, pp. 225-247.

Stanovich, K.E. and West, R.F. (2014), "The Assessment of Rational Thinking: IQ =/ RQ”, Teaching of Psychology, Vol. 41 No. 3, pp. 265-271.

Stanovich, K.E., West, R.F. and Toplak, M.E. (2013), "Myside Bias, Rational Thinking, and Intelligence", Current Directions in Psychological Science, Vol. 22 No. 4, pp. 259-264.

Staw, B.M. (1981), "The Escalation of Commitment To a Course of Action.", Academy of Management Review, Vol. 6 No. 4, pp. 577-587.

Staw, B.M. (1997), The Escalation of Commitment: An Update and Apprisal in Organization Decision Making, Zaphira., Cambridge University Press, Cambridge. 